\title{
Method of Reducing the Content of Fuel Oils Activation of the Alcohol Liquid
}

\author{
Vorobiev Yu $\mathrm{V}^{1}$ and Dunaev AV ${ }^{2 *}$ \\ ${ }^{1}$ Tambov state technical University, Russia \\ ${ }^{2}$ Federal research Center of Agricultural Engineering VIM, Russia
}

*Corresponding author: Dunaev AV, Federal research Center of Agricultural Engineering VIM, Russia.

Received Date: June 07, 2019

Published Date: July 02, 2019

\begin{abstract}
Environmental problems relate to food and wine-vodka products in terms of eliminating them from toxic substances. In this appears, although not cardinal, the possibility of a simple method to reduce the content of fuel oils in alcoholic liquids. This was tested for mechano-chemical activator liquids according to the Russia patent no 2411074. In it there is a destruction of organic substances and long-chain molecules of heavy oils are converted into light, safe compounds. So, in the activated «Cognac» acetone, ketone, isobutyl acetate and 2-butanol are completely removed, ethyl acetate is reduced by 2,3 times, six components of oils are reduced by $11.7 \%$, two components of complex esters by 8 times, and two components of alcohols increased by $17.9 \%$. Similarly, in conventional vodka acetaldehyde and acetone are removed, aromatic alcohols were less than 4 times, that of the ketone at 5.9 times. In wine «Cabernet» fuel oils reduced by 2,37 times, in white dry wine- 3 times, and sweet fortified wine- 100 times. Thus, the content of harmful substances in alcohol can be reduced by activator under the patent of Russia no 2411074 .
\end{abstract}

Keywords: Alcoholic liquid; Fuel oil removal; Mechano-chemical activator

\section{Introduction}

Since prehistoric times, it is known to ferment sugary and other materials to alcohols, extract harmful compounds from the fermented product and preserve useful ones. However, even in the industrial manufacture of noble beverages (cognac, brandy) by distillation, neutralization, purification and other methods, harmful substances are not completely removed.

During the primary distillation of fermented products, along with alcohol, a mass of harmful substances, including poisons: methanol, fuel oils, and other untreated compounds, is also distilled. The boiling point of alcohol is $78.4{ }^{\circ} \mathrm{C}$, and in fermented products there are liquids that boil at lower (methanol, acetone, acetaldehyde, etc.) and at higher temperatures (amyl, propyl, isoamyl and other alcohols, furfural, acetyl). Many of them are poisonous and dangerous to humans. However, during the processing of fermented products with the separation of fractions, with the removal of the most toxic impurities in the final product, there are still quite a lot of harmful components called fuel oils. In a high-quality alcoholic liquid should contain as little fuel oils but should be kept harmless substances. The approximate content of fuel oils in some products (Table 1).

Table 1: Approximate content of fuel oils in alcoholic liquids.

\begin{tabular}{|c|c|c|c|c|c|c|}
\hline $\begin{array}{c}\text { Alcoholic } \\
\text { liquid }\end{array}$ & Vodka & Beer & Wine & Cognac & Visci & $\begin{array}{c}\text { Home } \\
\text { Alcohol }\end{array}$ \\
\hline $\begin{array}{c}\text { Fusel oil } \\
\text { content, } \\
\mathrm{mg} / \mathrm{l}\end{array}$ & $5-15$ & $25-100$ & $\begin{array}{c}100- \\
630\end{array}$ & to 2000 & $\begin{array}{c}\text { to } \\
6000\end{array}$ & to 6500 \\
\hline
\end{tabular}

Fuel oils contain high-molecular alcohols, which are difficult to break down due to the complex composition of the human body. Therefore, the work human liver is complicated, the decontamination of toxins is slowed down, as from the management of the extended. To break down substances, they must be oxidized by blood oxygen. But the longer their molecules are, the more oxygen they need. When using large doses of alcohol blood supply is difficult, oxygen is not enough, so the toxins are not completely oxidized. In this case, things are formed more poisonous than methyl alcohol. With a large content of acetaldehyde, the possibilities of the liver to neutralize ethanol are sharply reduced, its proces-sing is delayed, 
and the concentration of acetaldehyde increases several times due to its further formed during the decay of ethanol.

In General, the product obtained after distillation of the initial fermented and fermenting substances contains impurities divided into groups:

1. Hats with a boiling point of $78.4{ }^{\circ} \mathrm{C}$ below: acetic-butyric ether, acetaldehyde, acetone.

2. Intermediate, as main components.

3. Tail (fuel oil) with a higher boiling point and lower volatility than ethyl alcohol: monoatomic alcohols: propyl, isopropropyl alcohol and its isomer, propanol-1, amyl, isoamyl, isobutyl and methyl alcohols, furfural, acetyl, ethyl acetate, ethyl butyrate and other toxic compounds; the most dangerous of them isoamyl alcohol (isoamyl alcohol $\mathrm{C}_{5} \mathrm{H}_{4} \mathrm{OH}$ ), giving up to $60 \%$ of the volume of fuel oils.

In fuel oil are also found: n-propyl, n-butyl, hexyl alcohols, diethyl ether, methyl acetate, methylpropionate, diacetyl, as well as acids: acetic, propionic, isobutyric, n-oil, isovalerian, n-valerian and more than 40 substances. And Isabella grapes during fermen-tation also produces hydrocyanic acid.

The largest amount of fuel oils produced from grain raw materials, when the alcohol raw them of $0.2-0.4 \%$. The content of fuel oils in vodka is limited by standards: for vodka «special purification»-no more than $15.0 \mathrm{mg} / \mathrm{l}$, for vodka «extra» up to $10.0 \mathrm{mg} / \mathrm{l}$, for vodka «Lux»- $5.0 \mathrm{mg} / \mathrm{l}$. In 0.5 liters of «normal» vodka on average contains $4 \mathrm{ml}$ of fuel oil. Especially dangerous isopropyl alcohol, which as its «cuts» a person, turns off consciousness, and possible death. For the average person, 1.5 liters of ordinary vodka is enough to get a lethal $(13-15 \mathrm{ml})$ dose of fuel oil.

Methods of cleaning from fuel oils: It is mainly used rectification of liquids, i.e. their separation into components (fractions) substances with a close boiling point. To do this, the liquid is heated to the boiling point and evaporation of the first fraction, it is kept heated and the first fraction is extracted by vapor condensation. Further, the temperature for evaporation of the second fraction is increased and it is similarly extracted as a useful raw material. After that, the distillation can be stopped.

The industrial method of cleaning from fuel oils is carried out in distillation columns in vertical cylindrical vessels of constant or variable cross section, equipped with heat and mass transfer devices and auxiliary units for the separation of liquids into fractions. The heated liquid is fed into the column from below, the light fractions are concentrated in the upper part of the column, and the heavy ones with a higher condensation temperature are concentrated in the lower part. Lack of rectification is the duration, complex, very cu-mbersome installation, high costs of thermal energy.

In private, alcohol purification is used by entering $3-5 \mathrm{~g} / \mathrm{l}$ of potassium permanganate ( $\mathrm{KMnO4}$ ) into them, settling for up to 10 days, precipitating a dark precipitate and draining the liquid without sediment. Enter also on $50 \mathrm{~g} / \mathrm{l}$ of wood activated carbon of industrial brands, defend liquid of 20-30 days, filter through paper or cotton filters with the activated carbon. Apply and freezing harmful substances, their deposition and draining the liquid without impurities. These long-term processes require freezers and other devices, special substances.

Innovation in alcohol purification: Tambov state technical University to clean alcohol from fuel oils tested combined static mixer-activator according to Russian patent No. 2411074 [1]. The peculiarity of the activator is that: it carries out mechano-chemical dispersion of long-chain organic liquids, passed through it $[2,3]$. The use of the activator simplifies the process, reduces the content of sea-wool oils by at least $10-13 \%$, some toxic substances in simple waters up to 3 times, esters by at least 8 times (Figure 1).

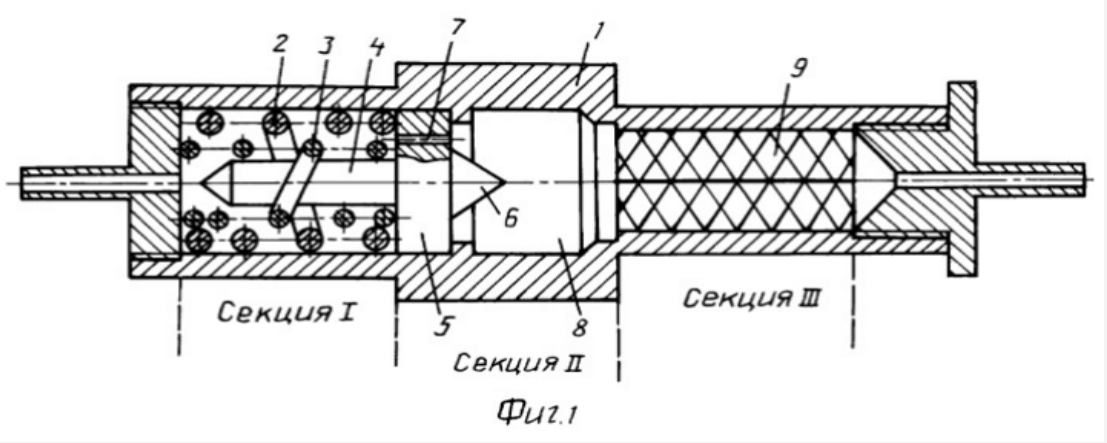

Figure 1: Diagram of the device of an activator according to the patent of Russia no 2411074 . The structure and operation of activator.

In the cylindrical housing 1 of the activator there are sections chambers I, II, III. In the section of the chamber I mounted the screws 2 and 3 . The screw 2 is adjacent to the inner surface of the housing 1 and has a right side or left side winding. Inside the screw 2 with a small gap mounted screw 3 with the opposite winding. Inside the screw 3 , also with a small gap, a rod 4 is mounted, combined with a disk 5 having a cone 6 on the reverse side.
In disk 5 microchannels 7 are made, the centers of which are located in the gap bet-ween the screws 2 and 3. For a disk 5 is mounted the second (II) cavitation section 8 , followed by sectionIII camera, which features a lattice design 9 with a narrow slit width of $0.1-0.5 \mu \mathrm{m}$, At the beginning, the liquid is controlled on a chromatograph for the initial content of harmful substances, then heated to $25-28{ }^{\circ} \mathrm{C}$. Setting the flow rate of the $10 \mathrm{~cm} / \mathrm{s}$, pump it 
through the activator. In it, in the first chamber, clusters of fuel oils are rubbed with vortex counter flows between the external and internal screws. Then the liquid is injected through microchannels into the second vacuum chamber rarefaction, where the molecules of the oils are dispersed cavitation. Finally, the liquid is pumped through the broken slots of the structure 9 of the third chamber, which finally disperse and activate the molecules of fuel oils and provide further activation of alcohol for a long period.

Therefore, liquids are kept for up to 30 days, the third time they control the content of fuel oils and when they are reduced by at least $10 \%$, they are given a liquid for processing or a finished Table 2: Complete results of the control components in cognac. product. Activation of alcoholic liquids not only reduces the content of fuel oils, but also increases the content of useful components in them.

Examples of testing method: 21.02.2018 «Cognac» checked on the content of organic components on the gas chromatograph «Cristallux-4000M» (with column HP-FFAP $50 \mathrm{mx0} / 32 \times 50 u m$ and detector PID-1) in Tambov certified laboratory of forensic and medical examination. Then the drink was pumped through the activator and similarly checked the content of the components (Tables 2,3).

\begin{tabular}{|c|c|c|c|c|}
\hline \multirow{2}{*}{ No } & The Number of Organic Compounds & \multirow{2}{*}{ Unit } & \multicolumn{2}{|c|}{ The Content of Compounds in Cognac: } \\
\cline { 3 - 5 } & Acetaldehyde & $\mathrm{mg} / \mathrm{dm}^{3}$ & 0.042 & After Processing in the Activator \\
\hline 1 & Acetone & $-\ll-$ & 5.595 & 0.045 \\
\hline 3 & Ethyl acetate & $-\ll-$ & 0.127 & 0.055 , Reduced in 2,3 times \\
\hline 4 & Methanol & $-\ll-$ & 0.000 & 0.000 \\
\hline 5 & $2-$ propanol & $-\ll-$ & 0.000 & - \\
\hline 6 & Ethanol & $-\ll-$ & $41.814,966$ & Removed completely \\
\hline 7 & Isobutylacetate & $-\ll-$ & 0.945 & Removed completely \\
\hline 8 & $2-$ butanol & $-\ll-$ & 0.863 & 2.944 \\
\hline 9 & 1-propanol & $-\ll-$ & 2.466 & - \\
\hline 10 & Isobutanol & $-\ll-$ & 0.000 & 0.036 \\
\hline 11 & Isoamylene & $-\ll-$ & 0.030 & 0.001 \\
\hline 12 & Hexanol & $-\ll-$ & 0.002 & 0.000 \\
\hline 13 & Benzaldehyde & $-\ll-$ & 0.001 & - \\
\hline 14 & Ethylbutyrate & $-\ll-$ & 0.076 & \\
\hline
\end{tabular}

Table 3: Summary results of control of components in cognac, The summarized results of the control components in brandy.

\begin{tabular}{|c|c|c|c|c|}
\hline \multirow{2}{*}{ No } & The Number of Organic Compounds & \multirow{2}{*}{ Unit } & \multicolumn{2}{|c|}{ The Content of Compounds In Cognac } \\
\cline { 3 - 5 } & Aldehyde & $\mathrm{mg} / \mathrm{dm} 3$ & The Original & After Processing \\
\hline 1 & Aldehydes & $-\ll-$ & 0.001 & 0.000 \\
\hline 2 & Ketone & $-\ll-$ & 5.042 & 0.045 \\
\hline 3 & Fusel oils (6 components) & $-\ll-$ & 3.361 & total removal \\
\hline 4 & Esters (2 components) & $-\ll-$ & 1.072 & 2.981 (minus 11,7 \%) \\
\hline 5 & Alcohol (2 compo-nents) & $-\ll-$ & $41.814,966$ & 492988 (plus 17,9 \%) \\
\hline 6 & & &
\end{tabular}

18.04.2018 vodka production was similarly tested on the content of toxic components, after which it was pumped through the actuator and checked again (Table 4, 5). From Tables 2-5 it follows, that activated the «Cognac» acetone, ketone, the isobutyl acetate and 2-butanol is completely removed, ethyl acetate is

Table 4: Changes in vodka content of component groups, Change in vodka content of groups of components.

\begin{tabular}{|c|c|c|c|c|}
\hline \multirow{2}{*}{ No } & \multirow{2}{*}{ Group of Compounds } & \multicolumn{2}{|c|}{ Concentration in Vodka } & \multirow{2}{*}{ Unit } \\
\cline { 3 - 5 } & & Original & Activated & $\mathrm{mg} / \mathrm{dm}^{3}$ \\
\hline 1 & Aldehydes & 0.002 & 0.000 & $-\ll-$ \\
\hline 2 & Aromatic alcohols & 0.008 & 0.002 , less than 4 times & $-\ll-$ \\
\hline 3 & Ketone & 1.288 & $0.218,5.9$ times less & $-\ll-$ \\
\hline 4 & Fusel oil & 0.000 & 0.001 & $-\ll-$ \\
\hline 5 & Ester & 0.011 & 0.040 & \\
\hline
\end{tabular}


Table 5: Changes in vodka content of organic compounds.

\begin{tabular}{|c|c|c|c|c|c|}
\hline \multirow{2}{*}{ No } & \multirow{2}{*}{ Compounds } & \multirow{2}{*}{ Group of Compounds } & \multicolumn{2}{|c|}{ Concentration in Vodka: } & \multirow{2}{*}{ Unit } \\
\hline & & & Initial & Activated & \\
\hline 1 & Acetaldehyde & Aldehyde & 0.002 & Removed & $\mathrm{mg} / \mathrm{dm}^{3}$ \\
\hline 2 & Ethyl ether & Compound ether & 0.010 & 0.024 & $-\ll-$ \\
\hline 3 & Acetone & Ketone & 1.268 & Removed & $-\ll-$ \\
\hline 4 & Methylacetate & Ester & 0.001 & 0.001 & $-\ll-$ \\
\hline 5 & Methanol & Alcohol & 0.000 & 0.000 & $\%$, volume \\
\hline 6 & 2-propanol & Fusel oil & 0.000 & 0.000 & $\mathrm{mg} / \mathrm{dm} 3$ \\
\hline 7 & Isoamylene & Fusel oil & 0.000 & 0.000 & $-\ll-$ \\
\hline 8 & Hexanol & Fusel oil & 0.000 & 0.001 & $-\ll-$ \\
\hline 9 & Benz alcohol & Aromatic alcohols & 0.008 & 0.002 & $-\ll-$ \\
\hline 10 & Ethyl acetate & Ester & - & 0.013 & $-\ll-$ \\
\hline 11 & 2-butanol & Ketone & - & 0.218 & $-\ll-$ \\
\hline 12 & Ethylbutyrate & Ester & - & 0.002 & $-\ll-$ \\
\hline 13 & Isobutanol & Fusel oil & - & 0.000 & $-\ll-$ \\
\hline 14 & Benz & Aldehyde & - & 0.000 & $-\ll-$ \\
\hline
\end{tabular}

\section{Other testing results}

1. In the wine «Cabernet» after activation the content of fuel oils decreased from $2,3 \mathrm{mg} / \mathrm{dm}^{3}$ to $0,971 \mathrm{mg} / \mathrm{dm}^{3}$, i.e. 2,37 times.

2. In white dry wine-3 times.

3. And in sweet fortified wine-100 times.

\section{Conclusion}

Activator according to the Russian patent no 2411074 allows you to simply and significantly reduce the alcohol content of harmful substances such as acetone, ethyl acetate, isobutyl acetate, 2-butanol, acetaldehyde.

\section{Acknowledgments}

None.

\section{Conflict of interest}

No conflict of interest.

\section{References}

1. Vorobiev Yu V, Teterukov VB. Combined static mixer-activator. Patent of the Russian Federation for invention no 2411074, Russia.

2. Vorobiev Yu V (2013) Fundamentals of the theory of mechanoactivation of liquid media. Bulletin of Tambov state technical University Tambov 19(3): 608-613.

3. Vorobiev Yu V, Kilimnik AB, Dunaev AV (2015) Reduction of fuel consumption of automotive internal combustion engines methods of mechanochemistry. Automotive industry 10: 21-22. 